\title{
A SUPERAÇÃO DA CONDIÇÃO DE SUBJUGAÇÃO DAS MULHERES E SEU SIGNIFICADO PARA A HISTÓRIA HUMANA \\ (O PENSAMENTO DE SIMONE DE BEAUVOIR EM DIÁLOGO COM O MATERIALISMO HISTÓRICO DIALÉTICO)
}

\section{LA SUPERACIÓN DE LA CONDICIÓN DE SUBJUGACIÓN DE LAS MUJERES Y SU SIGNIFICADO PARA LA HISTORIA HUMANA \\ (EL PENSAMIENTO DE SIMONE DE BEAUVOIR EN DIÁLOGO CON EL MATERIALISMO HISTÓRICO DIALÉCTICO)}

\author{
Patrícia Felden* \\ Paulo Vinícius Nascimento Coelho**
}

\section{RESUMO}

Desenvolvendo uma análise crítica sobre a condição da mulher na história (condição que por muito tempo se caracterizou, e ainda parece se manter, pela subjugação), a filósofa francesa Simone de Beauvoir dialoga com importantes correntes de pensamento como a Fenomenologia, Existencialismo e, em especial, o Materialismo histórico dialético, o qual destacaremos no presente trabalho, sublinhando as aproximações entre o pensamento de Beauvoir e o projeto social revolucionário do Socialismo Científico que parte da teoria materialista de Marx e Engels, destacando as noções de "alteridade e reciprocidade" e a intenção ética de superação da condição de subjugação das mulheres diante dos homens (superação a qual, em uma sociedade igualitária e livre, se supõe que pudesse ser realizada).

PALAVRAS-CHAVE: Beauvoir. Engels. Feminismo. Marx. Materialismo histórico dialético.

\section{RESUMEN}

La filósofa francesa Simone de Beauvoir dialoga con importantes corrientes de pensamiento como la fenomenología, existencialismo y, en el caso de la mujer, en la historia (condición que por mucho tiempo se caracterizó, y aún parece mantenerse por la subyugación) el materialismo histórico dialéctico, lo cual trataremos en este trabajo, subrayando los acercamientos entre el pensamiento de Beauvoir y el proyecto social revolucionario del socialismo científico que parte de la teoría materialista de Marx y Engels, fijando las nociones de "alteridad y reciprocidad" la intención ética de superación de la condición de subyugación de las mujeres ante los hombres (superación, la cual, en una sociedad igualitaria y libre, se supone que pudiera ser realizada).

PALABRAS CLAVE: Beauvoir. Engels. Feminismo. Marx. Materialismo histórico dialéctico.

\footnotetext{
* Possui graduação em Filosofia pela Universidade Federal de Santa Maria (UFSM). Atualmente é Mestranda em Filosofia na Universidade Federal de Santa Maria (UFSM), na linha de pesquisa Ética normativa, metaética e ética aplicada.

** Professor de Filosofia e Sociologia; Bacharel em Ciências Sociais, Licenciado em Filosofia e Especialista em Pensamento Político (UFSM); Mestrando em Filosofia-UFSM. E-mail: paulohidra@ hotmail.com.
} 


\section{INTRODUÇÃO}

Simone de Beauvoir considerava o "estereótipo" do "ser mulher" como um produto de um processo histórico gerado sob o peso de interesses masculinos os quais moldaram um padrão de comportamento, visto como o "ideal”, para o feminino; tal "padrão" seria (e ainda é) imposto às mulheres, geração após geração, com modificações próprias de cada época, mas sempre de acordo com interesses dos homens.

Não haveria para Simone de Beauvoir um "comportamento feminino" determinado biologicamente, tal seria imposto culturalmente sob determinados contextos históricos e sociais, e isso ocorreria em praticamente todas as sociedades humanas (talvez, com algumas raras exceções), obviamente de acordo com as peculiaridades de cada sociedade e época. Haveria, portanto, um peso histórico, social e cultural, sobre todas as mulheres, uma "violência simbólica" influenciando a formação da identidade dos sujeitos femininos, revelando uma hierarquia de poder entre masculino e feminino nas sociedades humanas, nas quais o feminino é apresentado como subalterno, inferior ao masculino.

Ao reconhecer a influência da história e das condições sociais sobre a formação da identidade dos sujeitos, a filósofa demonstra sua ligação com o Materialismo histórico o qual combinado com o Existencialismo (explícito na noção de que a "existência precede a essência”, ou seja, de que a identidade é construída sob condições reais durante a existência da pessoa), são essas fortes bases teóricas para a elaboração de sua análise sobre a condição da mulher nas sociedades humanas.

No presente trabalho destacaremos a influência do pensamento de Marx e Engels (o Materialismo Histórico Dialético em especial, e a proposta socialista) sobre a obra de Simone de Beauvoir e algumas críticas que a filósofa fazia a esses pensadores.

\section{MATERIALISMO HISTÓRICO DIALÉTICO E O SEGUNDO SEXO}

Na obra $O$ segundo sexo de Simone de Beauvoir, encontramos um diálogo entre Existencialismo e Materialismo histórico dialético; tal obra se destaca como uma importante referência para os movimentos feministas em âmbito internacional, um trabalho fundamental para a busca de melhor compreensão sobre a situação da mulher na história.

Beauvoir parte de um olhar crítico sobre as relações intersubjetivas que historicamente permitiram a constituição de códigos de feminilidade. A filósofa destaca que o 
feminino é pensado, com relação ao masculino, como um "Outro" para o qual não se atribuí positividade.

A famosa frase "ninguém nasce mulher: torna-se mulher" destaca como "o feminino" é moldado histórica e culturalmente, o que, predominantemente na história, ocorreu de acordo com interesses dos homens e sob condições de subjugação impostas às mulheres, condições que as fizeram permanecer por muito tempo submetidas à maternidade, no âmbito privado da família e vida doméstica. A própria humanidade seria uma realidade histórica e não apenas mero produto da natureza, mas, sim, constrói a si mesma enquanto espécie, transformando a natureza e a si; dessa forma, sob influência do Materialismo histórico, Beauvoir destaca a questão das mulheres nessa perspectiva:

\begin{abstract}
A teoria do materialismo histórico pôs em evidência muitas verdades importantes. A humanidade não é uma espécie animal: é uma realidade histórica. A sociedade humana é uma anti-phisis: ela não sofre passivamente a presença da Natureza, ela a retoma em mãos. Essa retomada de posse não é uma operação interior e subjetiva; efetua-se objetivamente na praxis. Assim, a mulher não poderia ser considerada apenas um organismo sexuado: entre os dados biológicos só têm importância os que assumem, na ação, um valor concreto; a consciência que a mulher adquire de si mesma não é definida unicamente pela sexualidade. Ela reflete uma situação que depende da estrutura econômica da sociedade, estrutura que traduz o grau de evolução técnica a que chegou a humanidade. (BEAUVOIR, 1970, p. 73).
\end{abstract}

Nas obras de Marx e Engels, Beauvoir identifica, também, uma abordagem sobre a questão da "alteridade e reciprocidade". A filósofa vê um ponto de ligação entre Materialismo histórico e sua própria obra e a possibilidade do reconhecimento da mulher como uma alteridade positiva posta em situação de igualdade e não como mero "Outro" em sentido negativo, tal poderia ser viável em uma sociedade que realizasse o projeto socialista, visto que todo problema da alteridade poderia ser resolvido em uma situação de plena igualdade.

[...] as ideologias socialistas que exigem a assimilação de todos os seres humanos não admitem que no futuro, e mesmo desde o presente, qualquer categoria humana seja objeto ou ídolo. Na sociedade autenticamente democrática que profetiza Marx não há lugar para o Outro. (BEAUVOIR, 1970, p. 182).

No entanto, seria necessário superar visões distorcidas e cultuadas pelos homens com relação ao que deve ser e simbolizar “ a mulher”, mas a condição de realização de igualdade social já seria um primeiro passo rumo ao reconhecimento positivo da mulher como parte fundamental da espécie e não meramente um complemento adicional para um sujeito que é 
tomado como "o modelo" do que é ou deve ser o "ente humano" (visto que o homem é tomado há tempos como a base referencial para se definir o que é "o humano").

Desenvolvendo um diálogo com o Materialismo Histórico, Beauvoir destaca que o trabalho seria uma das condições para as mulheres alcançarem independência. O trabalho é um meio pelo qual as mulheres podem se inserir propriamente no âmbito econômico da vida social, de uma forma ativa no modo de produção da sociedade em questão. Obviamente, como também defendia o socialismo, Beauvoir não acreditava que o trabalho em um contexto capitalista fosse a "salvação" para as mulheres, mas ponderava que esse já seria um passo importante no sentido de busca de independência, saída de uma situação de pesada subjugação em que as mulheres se encontravam no espaço restrito da vida privada.

Aos 77 anos, em entrevista, Simone afirmava:

Eu não recuso a maternidade. Acho apenas que é uma armadilha. O que se deve condenar não são as mães, mas a ideologia que incita as mulheres a serem mães e as condições em que devem sê-lo. Junta-se a isso uma mistificação perigosa da relação mãe-filho. Mesmo que uma mulher tenha vontade de ter filhos, deve refletir muito porque a maternidade, atualmente, é uma verdadeira escravidão. ... Se queremos ser independentes, o importante é ter uma profissão: esta é uma condição imprescindível. O trabalho não é uma panacéia. Sei muito bem que o trabalho, como é hoje, tem dois lados: um alienante e outro libertador que, por consequência, as mulheres têm frequentemente de escolher entre duas alienações: a do trabalho e a doméstica. Contudo, o trabalho não é apenas uma panacéia mas é, apesar de tudo, a primeira condição para a independência. (BEAUVOIR, 1985, p. 52).

Mesmo considerando aspectos biológicos (como a questão do corpo feminino e o potencial para a maternidade) e as peculiaridades da anatomia feminina, Beauvoir afirmava que o corpo por si mesmo não bastava para explicar a situação da mulher, visto que, também, é de certa forma "modelado" pelas condições históricas e sociais dadas, as quais serão básicas para direcionar o olhar interpretativo sobre o próprio corpo, sob influências de aspectos culturais atrelados à realidade política e social do momento histórico tomado como referência. Sendo assim, outros fatores devem ser levados em consideração, para além da mera constatação biológica.

É portanto, à luz de um contexto ontológico, econômico, social e psicológico que teremos de esclarecer os dados da biologia. A sujeição da mulher à espécie, os limites de suas capacidades individuais são fatos de extrema importância; o corpo da mulher é um dos elementos essenciais da situação que ela ocupa neste mundo. Mas não é ele tampouco que basta para a definir. Ele só tem realidade vivida enquanto assumido pela consciência através das ações e no seio de uma sociedade; a biologia não basta para fornecer uma resposta à pergunta que nos preocupa: por que a mulher é o Outro? Trata-se de saber como a natureza foi nela revista através da história; 
trata-se de saber o que a humanidade fez da fêmea humana. (BEAUVOIR, 1970, p. 57).

Beauvoir destacava o fato de que os dados biológicos são importantes apenas para tratar a questão da consciência que a mulher tem de si mesma e do valor socialmente atribuído às suas características físicas.

Em épocas em que a força física teve destaque, tal situação impôs uma condição de inferioridade às mulheres, no entanto Beauvoir (1970, p. 74) afirma que a diferença muscular que separa o homem da mulher está em uma perspectiva de necessidade: só cria propriamente superioridade na perspectiva de uma necessidade. Quando essa força passa a ser comparada na operação de novas tecnologias, máquinas modernas, por exemplo, a necessidade de grande esforço físico desaparece, possibilitando a qualquer sexo tal operação.

\begin{abstract}
Na história humana, o domínio do mundo não se define nunca pelo corpo nu: a mão com seu polegar preensivo já se supera em direção ao instrumento que lhe multiplica o poder; desde os mais antigos documentos de pré-história o homem surge sempre armado. No tempo em que se tratava de brandir pesadas massas, de enfrentar animais selvagens, a fraqueza física da mulher constituía uma inferioridade flagrante; basta que o instrumento exija uma força ligeiramente superior a de que dispõe a mulher para que ela se apresente como radicalmente impotente. Mas pode acontecer, ao contrário, que a técnica anule a diferença muscular que separa o homem da mulher: a abundância só cria superioridade na perspectiva de uma necessidade; não é melhor ter demais do que não ter bastante. [...] Se o mínimo necessário não é superior às capacidades da mulher, ela torna-se igual ao homem no trabalho. Efetivamente, pode-se determinar hoje imensos desenvolvimentos de energia simplesmente apertando um botão. (BEAUVOIR, 1970, p. 73-74).
\end{abstract}

Beauvoir lembra que, de certa forma, Engels seguia uma linha de interpretação semelhante no que diz respeito ao problema da subjugação feminina, relacionando as condições biológicas da mulher às mudanças tecnológicas e transformações na estrutura das sociedades humanas (modo de produção) para tentar explicar os motivos que teriam supostamente levado à situação de dominação dos homens sobre as mulheres.

Tomando como referência a obra A origem da família de Engels, a autora, por exemplo, destacava que, quando transformações ocorreram no modo de produção das sociedades da pré-história que ainda eram de caçadores e coletores nômades, sociedades as quais, com a agricultura, passaram a uma nova forma de divisão de trabalho, a relação entre mulheres e homens mudou drasticamente:

Com a descoberta do cobre, do estanho, do bronze, do ferro, com o aparecimento da charrua, a agricultura estende seus domínios. Um trabalho intensivo é exigido para desbravar florestas, tornar os campos produtivos. O homem recorre, então, ao 
serviço de outros homens que reduz à escravidão. A propriedade privada aparece: senhor dos escravos e da terra, o homem torna-se também proprietário da mulher. (BEAUVOIR, 1970, p.74).

Com o surgimento da família patriarcal baseada na propriedade privada (visto que a transmissão da propriedade passa a ser concedida apenas de pai para filho e não mais da mulher para seu clã), na esfera familiar a mulher torna-se oprimida. Mas Beauvoir pondera que mesmo com as mudanças tecnológicas que possibilitaram um domínio maior sobre a natureza, era preciso pressupor algo a mais para realmente compreendermos o que levou à submissão forçada da mulher, identificar o que na própria condição humana incitaria ou daria base "ontológica" para essa divisão na espécie.

Se a relação original do homem com seus semelhantes fosse exclusivamente uma relação de amizade, não se explicaria nenhum tipo de escravização: esse fenômeno é consequência do imperialismo da consciência humana que procura realizar objetivamente sua soberania. Se não houvesse nela a categoria original do Outro, e uma pretensão original ao domínio sobre o Outro, a descoberta da ferramenta de bronze não poderia ter acarretado a opressão da mulher. (BEAUVOIR, 1970, p. 7778).

Portanto, fatores econômicos e meramente materiais não são suficientes para explicar a situação da mulher, aliás, não seriam suficientes para explicar nem mesmo o que realmente motivou a própria divisão de classes das sociedades humanas.

Em $O$ segundo sexo encontramos uma abordagem crítica, e do campo da filosofia Moral, sobre as relações intersubjetivas que historicamente permitiram a constituição de códigos de feminilidade que condicionaram e condicionam o "estado atual da educação e dos costumes" que afetam as mulheres, mas que dizem muito sobre uma divisão hierárquica, injusta, que acompanha a humanidade desde tempos remotos: a desigualdade de condições entre homens e mulheres e a forçada subjugação feminina aos interesses masculinos.

Ninguém nasce mulher: torna-se mulher. Nenhum destino biológico, psíquico, econômico define a forma que a fêmea humana assume no seio da sociedade; é o conjunto da civilização que elabora esse produto intermediário entre o macho e o castrado, que qualificam de feminino. (BEAUVOIR, 1967, p. 9).

O processo investigativo de Beauvoir sobre "o feminino" começa pela busca de uma compreensão dialética da condição histórica das mulheres e uma análise ética sobre a ação dos sujeitos humanos, partindo da noção existencialista de "Para si" e de uma análise sobre o processo de autoconstrução dos sujeitos, sob circunstâncias históricas e culturais. 
Beauvoir aponta em $O$ segundo sexo a permanência de um "maniqueísmo" nas culturas humanas, algo que, com um olhar atento, analisando narrativas míticas e observando o comportamento de indivíduos humanos em sociedade, podemos identificar: uma tendência humana a dispor as coisas em relações de dualidade ("bem x mal”, "luz x escuridão", "Deus x Lúcifer", "amigo x inimigo"...) e a assumir a atitude de identificar "os semelhantes" e apontar os "diferentes", em um jogo do "nós contra os outros".

(...) a alteridade é uma categoria fundamental do pensamento humano. Nenhuma coletividade se define nunca como Uma sem colocar imediatamente a Outra diante de si. Basta três viajantes reunidos por acaso num mesmo compartimento para que todos os demais viajantes se tornem "os outros" vagamente hostis. (BEAUVOIR, 1970, p. 11).

Quando um determinado grupo humano se afirma como "uma unidade", como consequência identifica outros grupos como "os outros". Obviamente isso pressupõe uma relação de reciprocidade, no sentido de que o primeiro grupo será, também, encarado como “outro" pelos demais, tal relação pode ser identificada, por exemplo, quando um povo encara outro como "estrangeiro". Em tal situação há o reconhecimento das características próprias do "outro" e não uma imposição ao "outro" do que o "outro" "deveria ser", embora, não podemos desconsiderar a influência da "ignorância" e do "temor" nessa relação, o que gera muitas vezes o preconceito ao se tentar classificar o "outro" e muitas vezes identificá-lo como inferior. Mas, há uma relevante diferença entre "olhar o outro sob a influência de preconceito ou ignorância" e, de outro lado, "tentar moldar o outro de acordo com a forma que se imagina ser o ideal" o "como o outro deveria ser" e ainda negar ao "outro" qualquer função ou dignidade na vida da sociedade caso não se enquadre no "ideal imposto". No extremo desse tipo de situação há a negação da própria condição humana do "outro". Podemos dizer que essa segunda situação, em que há a tentativa de moldar o outro (de acordo com o interesse e vontade de alguém que se assume como modelo superior em uma escala hierárquica) é o que acontece há tempos na história das sociedades humanas na relação entre homens e mulheres, na qual o masculino tenta impor seu desejo do "que deve ser uma mulher" sobre o feminino. Essa é uma divisão que se apresenta dentro de todas as sociedades humanas, em maior ou menor grau, e isso independentemente do embate entre classes ou dos conflitos étnicos ou mesmo ideológicos, pois mesmo dentro de partidos ou movimentos políticos organizados, ou mesmo dentro de uma etnia (tentando se afirmar contra a pressão de outra), as mulheres ainda 
são vistas como subjugadas aos interesses dos homens e o machismo ou "o peso do patriarcado" se faz notar.

Beauvoir, dialogando também com a obra de Lévi-Strauss, destaca que a tendência a se pensar as relações biológicas $s$ ob a forma de sistemas de oposições ${ }^{1}$ seria inerente à vida social, consequência do processo de passagem "do estado natural para o cultural", no entanto, tal tendência não negaria a reciprocidade nas interações entre os homens, o reconhecimento da "identidade" do outro, o que, infelizmente, não acontece quando o outro é a mulher; diante disso Beauvoir coloca a pergunta:

\begin{abstract}
Como se entende, então, que entre os sexos essa reciprocidade não tenha sido colocada, que um dos termos se tenha imposto como o único essencial, negando toda relatividade em relação a seu correlativo, definindo este como a alteridade pura? Por que as mulheres não contestam a soberania do macho? Nenhum sujeito se coloca imediata e espontaneamente como inessencial; não é o Outro que definindose como Outro define o Um; ele é posto como Outro pelo Um definindo-se como Um. Mas para que o Outro não se transforme no Um é preciso que se sujeite a esse ponto de vista alheio. De onde vem essa submissão na mulher? (BEAUVOIR, 1970, p. 12).
\end{abstract}

As mulheres são educadas de acordo com valores e normas de conduta que estão de acordo com os interesses masculinos, e isso é alimentado geração, após geração criando um ambiente cultural hierarquizado no qual à mulher é negada a reciprocidade e lhe é imposto e exigido um padrão de comportamento e formas de agir que nada mais são do que uma caricatura de um "ideal de feminino" imaginado pelos homens; essa situação expressa uma injustiça permanente dentro da espécie humana, algo que se perpetua independente do grupo social, político ou cultural, ao qual possamos nos referir, pois em todos é negada às mulheres a dignidade de construírem para si mesmas suas próprias identidades de forma livre.

De um ponto de vista ético, falar na superação da condição de subordinação das mulheres às vontades dos homens é falar na liberdade da própria humanidade, uma humanidade que poderá se tornar mais completa no momento em que reconhecer autonomia para a metade ainda subjugada de si mesma, chegando a uma situação de igualdade e superação da divisão interna da espécie, em ambiente realmente propício para a expressão da liberdade, tal como almejam os ideais socialistas:

\footnotetext{
1 “A passagem do estado natural ao estado cultural define-se pela aptidão por parte do homem em pensar as relações biológicas sob a forma de sistemas de oposições: a dualidade, a alternância, a oposição e a simetria, que se apresentam sob formas definidas ou formas vagas, constituem menos fenômenos a serem explicados que os dados fundamentais e imediatos da realidade social" (LÉVI-STRAUSS apud BEAUVOIR, 1970, p. 11).
} 
[...] é quando for abolida a escravidão de um a metade da humanidade, e todo o sistema de hipocrisia que implica, que a "seção" da humanidade revelará sua significação autêntica e que o casal humano encontrará sua forma verdadeira. "A relação imediata, natural, necessária do homem com o homem é a relação do homem com a mulher", disse Marx. "Do caráter dessa relação decorre até que ponto o homem se comprometeu com o ser genérico, com o homem; a relação do homem com a mulher é a relação mais natural do ser humano com o ser humano. Nela se mostra, portanto, até que ponto o comportamento natural do homem se tornou humano ou até que ponto o ser humano se tornou seu ser natural, até que ponto sua natureza humana se tornou sua natureza". Não há como o dizer melhor. É dentro de um mundo dado que cabe ao homem fazer triunfar o reino da liberdade; para alcançar essa suprema vitória é, entre outras coisas, necessário que, para além de suas diferenciações naturais, homens e mulheres afirmem sem equívoco sua fraternidade. (BEAUVOIR, 1967, p. 500).

\section{CONCLUSÃO}

A situação de subjugação da mulher revela uma injustiça escancarada que acompanha a história da espécie desde tempos primordiais, algo que incita a um posicionamento ético, exige uma tomada de posição, por colocar em xeque qualquer pretensa proposta de transformação social radical das sociedades humanas, pois, sem ultrapassar tal situação, qualquer ideal de igualdade e liberdade soará sempre um engodo. Mas Beauvoir reconhece a dificuldade de tal problema ser encarado sobriamente pelos homens, pois há sempre uma tendência em se buscar a manutenção de privilégios; portanto, caberia às próprias mulheres lutarem por dignidade, o que, também, obviamente, exige que percebam a situação em que se encontram, o que nem sempre ocorre, dado o aprofundamento de uma visão de subalternidade das mulheres propagada por centenas e centenas de anos, geração após geração, conduzindo a educação das meninas (a ponto de que as próprias mulheres, muitas vezes, reproduzam o machismo diante de outras mulheres).

A disparidade hierárquica entre homens e mulheres, algo que se perpetua no decorrer da história da espécie e aparece em quase todas as sociedades, classes, etnias, grupos culturais e políticos, ferindo não apenas a dignidade das mulheres, mas, da própria espécie, é uma situação que precisa ser superada para que possamos realmente pensar em um projeto ético consistente para a humanidade, tal como aspirado pelo socialismo científico.

\section{REFERÊNCIAS}

ANDERSON, P. Considerações sobre o marxismo ocidental. São Paulo, Brasiliense, 1989 [1976]. 
BEAUVOIR, S. de. O segundo sexo: fatos e mitos. Tradução Sérgio Milliet. 4. ed. São Paulo: Difusão Europeia do Livro, 1970.

BEAUVOIR, S. de. O segundo sexo: experiência vivida. Tradução Sérgio Milliet. 2. ed. São Paulo: Difusão Europeia do Livro, 1967.

BEAUVOIR, S. de. "Não se nasce mulher. Torna-se mulher". Revista Claudia, n. 291, 1985, p. 52.

ENGELS, Frederick. A origem da família, da propriedade privada e do estado. São Paulo: Ed. Civilização Brasileira, 1984.

MARX, k. Manuscritos econômico-filosóficos de 1844. Tradução de Jesus J. Ranieri. São Paulo, Boitempo, 2004.

LÉVI-STRAUSS, Claude. Estruturas elementares do parentesco. Petrópolis, RJ: Vozes, 2012. 